\title{
Lessons for Theory: A Conceptual Framework of Transformative Pathways
}

A major objective of this book is to provide theoretical and practical knowledge on how sustainable, low-carbon transformation can be facilitated. As a creative and a rational process, transformation can be managed. However, the management of transformation necessitates an integrative and process-oriented outlook to grasp the various issues, dynamics, causalities, associative relations, lock-ins, critical junctures, tipping points, interactions, behavior, and analytical levels that drive any transformation process. Chapters 2 to 6 have contributed to the theoretical framework or scope of the book, followed by chapters 7 and 8 , which presented the knowledge and decision tools as methodologies (the ideal types as theoretical models, case studies and simulations). These tools guided the analysis of the case studies in chapters 8 to 12 . These case studies offered the empirical foundation by providing the context, agency, and audience relevant to the transformation process of selected countries. This chapter delivers the next step, which introduces a conceptual framework to better understand and explain 'stratified' transformative pathways from the 'negotiative' perspective.

A. M. Hernández, Taming the Big Green Elephant, Globale Gesellschaft und internationale Beziehungen, https://doi.org/10.1007/978-3-658-31821-5_13 
The Conceptual Framework of Transformative Pathways (CFTP) attempts to provide an important understanding necessary to grasp the complexity of shifting from the initially chosen or assumed pathway ('business-as-usual') to other pathways, which in this book are referred to as sustainable, low-carbon (transformative) pathways. As a framework, the CFTP will provide an explanation of causality (referred to here as 'congruence'). This explanation will be substantiated using previous works in relevant fields including well-established theories, as well as the case studies (including the simulation game) presented in this book. Afterwards, the assessment of the congruence (or explanation)'s ability to predict will be assessed, testing its possible reoccurrence in future events as well as its applicability to other contexts. Another possibility of testing the ability to predict is to provide insights into which conditions this congruence can occur. The testing will be ended by discussing its limitations and analyzing to what extent this congruence can be falsifiable. An important disclaimer of this chapter is that this conceptual framework is still being developed and will eventually reach maturity as time passes.

\subsection{The Parameters of the Conceptual Framework of Transformative Pathways-The Negotiation Outlook}

The following figure mirrors the integrated stream of transformation. Before introducing the various phases of transformative pathways, there is a need to discuss some important characteristics of the illustration (Fig. 13.1). 


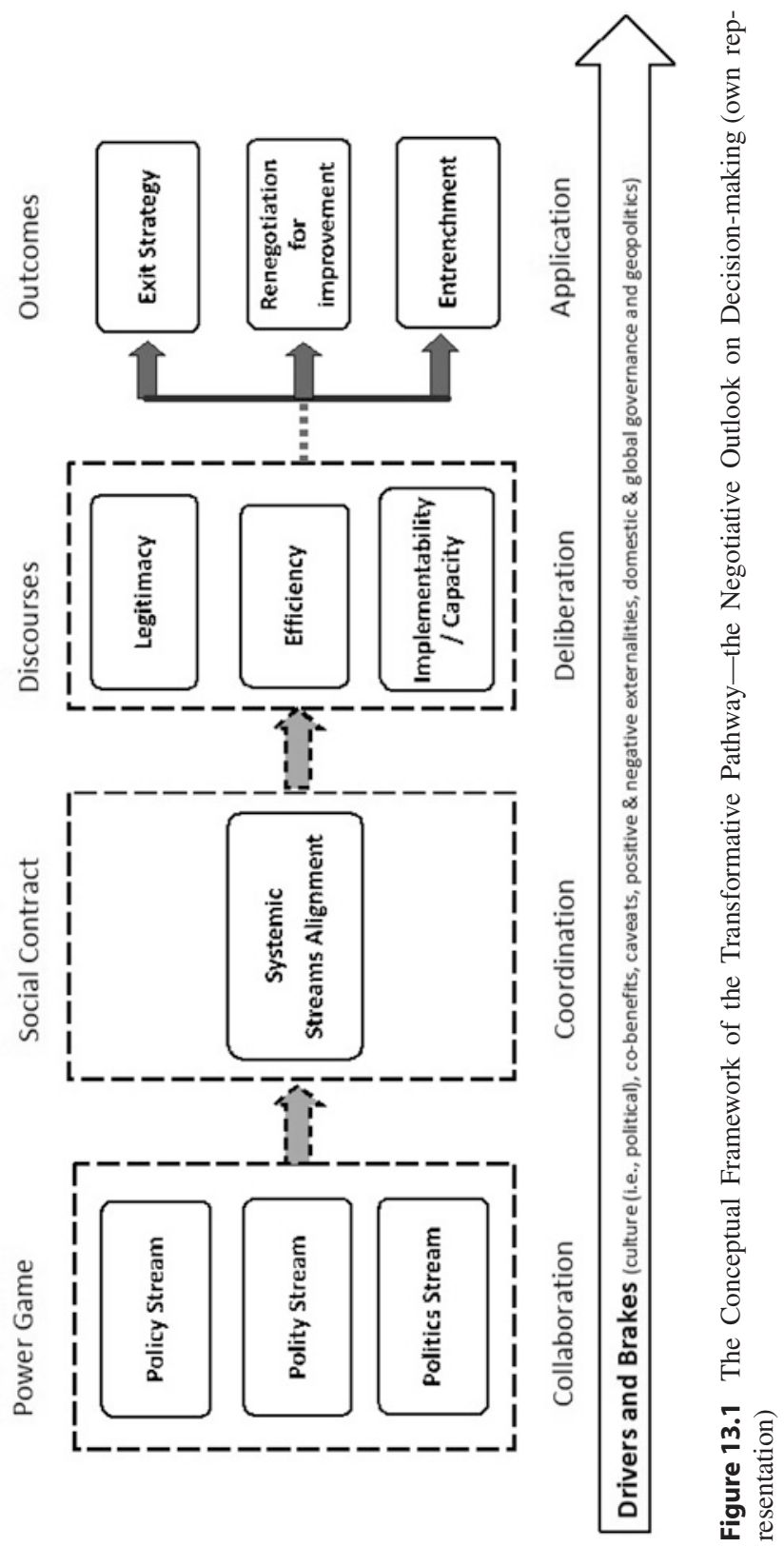


The non-linear process projects decision-making at both the global and domestic levels, where there are evident deviations, particularly because of the varying types of exogenous interventions, the varying implications of public goods in terms of exclusion, as well as the diversity in the range of capacities. It cannot be automatically assumed that the global/domestic is merely a question of scaling or abstraction, because while these two rationales are interrelated, they can also influence each other. For example, the global can limit the ability of the domestic to shift its energy system. Nevertheless, the 'vertical' hierarchy between the 'global' and the 'domestic' needs to be assumed as an explanatory variable of distinct dynamics. For example, Anthony Bogues (2011) argues that the national is the self and the global is the other, which posits a hierarchical process that distances the self from the other. In this sense, the domestic is the self and the global is 'everyone else on the international stage.' There is a need to highlight the fact that the boundary between the global and the domestic is diffuse, as conflicts, vulnerabilities, value systems, institutions, and technologies are conflated. As the politics of Jawaharlal Nehru represented, there cannot be an internationalist who is not a nationalist (Chacko 2011).

Moreover, while the 'domestic' indicates the concept of citizenry following the norms bestowed by state sovereignty, the 'global' is itself still in the process of exploring the possibility of a world citizenship (see Roscrance 1998; Dunne 2008). A huge barrier to this is the somewhat exclusive nature of public spheres, in which a public sphere is connoted to exist only through the mobilization of an identity. If the European Union is to be taken as the best example of the possibility of a 'post-national constellation' (see Calhoun 2002; Zürn 2002, 2009), the limitations of extending 'European Union citizenry' have become evident. Jürgen Habermas' (2006) suggests that the new, European public sphere, while previously offering hope of a true world citizenship, has becomes bleaker, as social movements in many European countries have emerged, demanding the reversal of this outward extension of European citizenry. To address the gap between the global and the domestic, this proposed conceptual framework assumes that the 'global' professes to be a certain degree of citizenry that can be decoupled from the principles of state sovereignty, a citizenry based on human solidarity (Arendt 1958; see Bogues 2011). This concept of citizenry based on solidarity can be compared with the idea of an 'internationalist nationalism' initially introduced by Priya Chacko (2011 p. 181).

The stages of interaction serve as spaces for the three types of interactions: functional, institutional, and bargaining interactions. As described in the previous chapters, because spheres and interests often overlap, interactions are necessary to address common vulnerabilities. Functional interactions highlight the overlap 
of mandates or visions. Institutional interactions refer to interactions between polities, where each represents 'embodied' distinct norms, principles, and practices, which are often self-enforcing. Bargaining interactions refer to interactions between actors that have the main goal of building alliances and partners through changes in the others' preferences and dispositions. They also refer to interactions between stakeholders, with the main purpose of exchanging values with or without changing the preferences of their counterparts.

The analysis of the different outcomes of functional, institutional, and bargaining interactions allows the integrative understanding of (domestic) collective actions that will be reflected by the behavior of this collectivity (or state) at the international and domestic level. At the international level, similar interactions occur, leading to another set of collective actions; however, the 'global' collectivity can deviate significantly from the 'domestic' collectivity (and vice versa), primarily because of the possibility of several types of interventions that are often defined in terms of sanctions and rewards. The 'prisoner's dilemma' game has a different meaning, for example, for global relations when confronted by Realpolitik in global relations or by low social capital than it does for intra-state relations.

In addition, because interactions are influenced by drivers and brakes (e.g., culture, co-benefits, and externalities), the transformation process can only be conceptualized through its contextual relevance and is therefore historical. Going back to the global/domestic juxtaposition, the contextualization of the global and the domestic can be transferred using two directions. The global context can be translated to the national context and the national context to the global context, where gaps can be evident, as some elements get 'lost in translation.' The global context is not the aggregation of all national contexts, because it is also an outcome of various unique interactions (that cannot be repeated), where some actors or issues can dominate the various processes under present conditions, leading them to dictate the parameters of the global context (of that time). In the same manner, some elements of the global context can be instilled back into the domestic level, where additional elements emerge as counter-reactions, particularly when conflicts of values, ideologies, and relationships become evident.

Decision-making requires some basis or points of reference for orientation. This highlights the cognitive, hence, human character of the transformation processes. As the illustration above suggests, the process is divided into four cognitive frames: social contract, power game, discourses, and outcomes. These cognitive frames are stable constructs that provide a lens that allows individuals to see and understand the situation and to create a context for complex behavioral responses (Walsh 1995; see Smith \& Tushman 2005). These frames promote the development of mind-sets useful to processing information and to engaging 
learning. For example, in the 'social contract' frame, actors are most likely keen on maximizing their influence when drafting the provisions (e.g., standards) of the social contract, as this social contract will later determine rewards and sanctions. Actors may therefore employ distinct competitive strategies, creating a coordination problem. Furthermore, actors require useful information to allow them to anticipate the consequences of each provision. In most cases, an inability to assess the provisions inhibits participation and increases the probability of defection in those cases where the social contract is implemented. As the process unfolds, the same actors will change and adapt their strategies, depending on the frames.

Corresponding with the cognitive frames are the stages of (cooperative) interaction: collaboration, coordination, deliberation, and application. These are derived from the four categories of cooperation problems (Stein 1983; Martin 2010; see Snidal 2010), which are here taken as stages or phases that are useful in conceptualizing the various related problems of collective actions: collaboration problems, coordination problems, deliberation problems, and application problems. While the cognitive frames pertain to the constitution of collective action, the stages of interaction concur in the relationships among actors, between issues, and between structures \& actors. For example, when actors assume and experience asymmetrical interests, they are confronted with an equilibrium outcome that leaves at least one actor dissatisfied. As institutions facilitate cooperation, coordination problems can be resolved, promoting the integration of interests in the deliberation and application stages.

\subsection{A Conceptual Framework of Transformative Pathways-The Congruence and Theorization of Causalities and Associations}

As described earlier, this section will introduce and discuss relevant 'congruence', which pertains to the explanations of causalities as identified in the previous chapters.

A congruence can be expressed through one of the following formulations:

\section{1) If $X$... then $Y$}

In this case, $\mathrm{X}$ is the explanatory variable for $\mathrm{Y}$.

2) $X$ is associated with $Y, Z$...

In some cases, $\mathrm{X}$ can only be partly or indirectly explained through the occurrence of $\mathrm{Y}$ and $\mathrm{Z}$, or only in conjunction with certain factors. 
In addition, a congruence will be theorized by the following steps:

1) Validation through substantiation: This involves an analysis using existing theories and empirical evidence collected from both the case studies \& simulation games, and from empirical data, models, \& expert judgment. The challenge is to find the explanatory value without losing substantive meaning as the value is generalized.

2) An analysis of the ability to predict: This pertains to the analysis of the possibility of reoccurrence in the future as well as its applicability to other contexts (or under which conditions it can occur in other contexts)

- The ability to predict also refers to the level of confidence based on expert judgment, data, and theory. This project uses the IPCC's likelihood scale in describing this level of confidence (see Moss \& Schneider 2000; IPCC 2005), as summarized in the following Tab. 13.1:

Table 13.1 Likelihood Scale (see Moss \& Schneider 2000; IPCC 2005)

\begin{tabular}{l|l}
\hline Term & Likelihood of the Outcome \\
\hline Virtually certain & $99-100 \%$ probability \\
\hline Very likely & $90-100 \%$ probability \\
\hline Likely & $66-100 \%$ probability \\
\hline About as likely as not & 33 to $66 \%$ probability \\
\hline Unlikely & $0-33 \%$ probability \\
\hline Very unlikely & $0-10 \%$ probability \\
\hline Exceptionally unlikely & $0-1 \%$ probability \\
\hline
\end{tabular}

3) Falsifiability: an analysis of the limitations and scope of the explanations and under which conditions the explanation will not be viable - Variable y will very likely not occur if $\mathrm{z}$.

Congruence 1: At the domestic level, if the levels of capacity and autonomy of the state facilitating the transformation process are low, then defection from the state-sponsored transformative pathway will be very likely.

Most literature on statehood refers to state capacity and state autonomy as indicators of state power (see Krasner 1984; Kreuzer \& Weiberg 2005; Chernillo 2007; Back \& Hadenius 2008). A state with high capacity and high autonomy is one that can provide basic tasks (including welfare services and security) and that is 
able to do so with a minimum of intervention from the public. A state with low capacity and low autonomy is one that lacks the ability to fulfil basic tasks and is subject to direct public control and interference. It is also one where power is highly decentralized among state and non-state actors. It needs to be highlighted that both democratic and authoritarian states can have high capacity and high autonomy, whereas having high autonomy tends to undermine democracy, as participation is limited. In the context of sustainable, low-carbon transformation, a state with high capacity and high autonomy will very likely find it easier to design sustainable, low-carbon transformation policies. Nevertheless, it needs to be asked how this high capacity and high autonomy has been achieved. Is it because of high social capital, where the public opts not to intervene, because it sees no reason to do so as the state can be generally trusted to seek policies that benefit all? Or is it because the public is completely excluded from decision-making?

The case study on China suggests that even an authoritarian country can find ways to balance efficiency and legitimacy. In lieu of the normative bias favoring democratic regimes, explanations are often sought as to how an authoritarian regime such as that in China can still manage to 'survive.' A likely explanation as to how China found a way to legitimate its institutions without requiring the 'concordant' process of deliberative decision-making can be offered by the possibility of strategically facilitating (or even manipulating) the approval process in front of the designated audience. Understanding this approval process is key to the success of the Chinese regime in achieving its audience's approval. In his book "The English Constitution," Walter Bagehot (1867) contended that the principles of the division of power (between legislature, executive, and judiciary) and of checks and balances (between the different elements of the constitution) are 'erroneous.' He identified the two elements of state institutions in the United Kingdom as the "dignified" and the "efficient." These two elements can explain how this approval process can be facilitated. The "dignified" parts played the essential role of winning and sustaining the loyalty of the public (input legitimacy) and the "efficient" parts were responsible for the technical aspects to ensure that goals were reached (output legitimacy). Using the general logic of these two elements, China's institutions have evolved to reflect a dualism of governance in terms of its institutions. China has developed state institutions that not only allow but are also dependent on the coexistence of the 'efficient' and the 'dignified.' The 'dignified' pertains to the parts that represent the political elite, whose members are recruited from the communist party cadre. The 'efficient' pertains to the technical elite whose members are recruited based on their technical expertise. With the integration of these two parts, China can fulfil both the political as well as the technical requirements of the transformation process. 
Meanwhile, as the Mexican and Philippine case studies confirm, democracy, when confronted by deficiencies, cannot guarantee to promote transformation process towards sustainability. The dominance of institutional activists and social movements in the country indicates a Philippine State with low capacity and low autonomy. The low capacity and low autonomy of the Philippine State are both a cause and an effect. In the case of Mexico, the lack of venues or channels for the effective participation of societal groups can be held responsible for the states low capacity. These societal groups could have contributed important inputs to the effective implementation of relevant energy projects. On the one hand, this situation reinforces the ability of dominant actors to disconnect various bargaining games from policy games. For example, as institutional activists willingly or unwillingly opt to reinforce existing structural imbalances and use privileges previously reserved for the dominant actors, the transformation process is very likely inhibited, because this disconnect will very likely mobilize 'preference outliers' leading to the proliferation of fractal systems. The disconnection of various bargaining games will very likely, on the other hand, lead to further limitations in the Philippine State's autonomy. Because sustainable, low-carbon transformation will virtually certainly touch on various interconnected issues, the State will virtually certainly need insurmountable resources to integrate the dispersed fractal systems of decision-making.

In addition, as the case study and simulation on Jamaica suggest, the level of capacity and autonomy of the state can also be associated with existing lock-ins. Jamaica's carbon lock-ins limit the set of possible decisions aiming at implementing sustainable, low-carbon transformation, implying both the low capacity and low autonomy of the Jamaican state. Such lock-ins create, among other things, institutional barriers, which further limit the synergies emerging from functional, institutional, and bargaining interactions. For example, Jamaica's dependence on international loans is associated with the country's rather small public sector, preventing the state from effectively facilitating and participating in various functional, institutional, and bargaining interactions, which would have introduced much needed impulses to resolve such lock-ins. Due to the wide-ranging and often cross-sectoral responsibilities of many government officials in Jamaica, they likely lack the detailed and integrated knowledge of sustainable energy technologies, their economic and financial requirements, and alternative mechanisms for their effective support.

Nevertheless, the level of capacity and autonomy of the state is highly contingent on how the state can 'depoliticize' and 'securitize' certain issues. The securitization of certain issues will likely initiate "emergency powers", allowing change agents to tap "exemptions" to the "normal" set of rules and regulations, 
in order to better address the existing constraints caused by lock-ins. The case study on China exemplifies how China was able to do a complete turn-around on its environmental and climate protection policies. Through the effective securitization of environmental and climate protection, China was able to revise its socio-linguistic narratives and justify the establishment of a "new normal." These narratives that, for example, link the need to address climate change with China's economic competitiveness, provided the regime with important capital to establish the "new normal" within limited constraints from many types of carbon lock-ins.

Congruence 2: The increasing relevance of fractal decision-making systems in the context of sustainable, low-carbon transformation at both the global and domestic level is virtually certainly associated with the frequent occurrence of disconnections between various bargaining and policy games. Fractal decision-making likely imposes a polycentric order, both at the global and domestic level.

As more bargaining games are disconnected from policy games, decision-making becomes virtually certainly polycentric. Furthermore, as each issue is separated from other issues, where the state encourages public participation in one issue but limits or excludes another issue, governance will likely become polycentric (see Ostrom 2010). The autonomy of the state decreases as more fractal decision-making systems (with each of these fractal systems seeking its own specific equilibrium) emerge, due to the increased polycentrism of governance. This means that the state becomes less capable of constituting and implementing policies by itself. The state will need to address multiple competitions within each of these fractal systems, which strain the state's capacity. The state will likely prioritize certain issues and delay or even resign in others, leading to individual vacuums in certain issues. These vacuums will likely further reinforce fractal systems. In such a situation, in facilitating and managing sustainable low carbon transformation, the State will virtually certainly be dependent on multiple fractal decision-making frameworks, which will virtually certainly exacerbate both the collaboration problem (e.g., the emergence of more equilibria) and the coordination problem (e.g., an increase in problems related to communication).

In the case study of the United States, the emergence of 'smart' cities and 'smart' enclaves as well as the re-emergence of social movements following the state's increased outsourcing of welfare services to the private sector will likely further undermine the autonomy of the state through the reinforcement of technocratic and post-democratic governance principles in the country. As the private sector and social movements continue to set the standards, benchmarks, and norms in various sectors and establish de facto 'expert committees' that compete 
with state institutions in terms of authority and expertise, the state will very likely be more dependent on the private sector and other non-state actors when implementing a wider range of policies, which will virtually certainly further exacerbate legitimacy deficits. These de facto 'expert committees' are informal conglomerates of technical experts that compete with experts within state polities. In addition, the dependence on de facto 'expert committees' will likely aggravate polycentric decision-making, because these de facto 'expert committees' will likely be sectoral in nature. Cross-cutting expertise is likely limited due to the corporate nature of accountability. For example, members of de facto 'expert committees' on financial issues will very likely come from the finance sector and have limited exposure to related social issues. In addition, because they are accountable to the stakeholders of the finance sector, there will very likely have limited motivation to encompass, for example, human rights concerns.

Therefore, the success of the transformation process depends virtually certainly on how the objectives of the transformation process can be aligned with the objectives of these de facto 'expert committees.' In addition, the increased importance of these de facto expert committees will virtually certainly lead to further legitimacy gaps in the transformation process. Hence, new forms of accountability and transparency are needed to address new types of structural imbalances.

\section{Congruence 3: The diffusion of norms, principles, and standards within a system is very likely associated with the identity-based concept of citizenry, both at the global and national level, because citizenry underpins the flow of social practices among actors.}

As implied earlier, the convergence of norms and values that resolve coordination and collaboration problems professes a certain degree of identity-based citizenry. Nevertheless, there is a need to consider an understanding of citizenry that is decoupled from the principle of state sovereignty, because this is often used as a pretext for exclusion. Several authors have called for similar concepts (see Arendt 1958; Bogues 2011). For example, Priya Chacko (2011 p. 181) introduced the idea of an "internationalist nationalism." When analyzing any transformation process, there is a need to identify the various categories that can unify actors, including both the change and status quo agents. For convergence to be initiated, respective norms, values, and principles need to be diffused to the value systems of the others, without causing ruptures in these systems. However, this diffusion presumes one or more entry points. Another idea about diffusion is contributed by David Strang and John Meyer (2010 p. 150), who argue that diffusion is shaped and accelerated by culturally-analyzed similarities among actors, and by theorized accounts of actors and practices. They continue by suggesting that when 
social entities belong to a common social category, diffusion should be rapid. As convergence moves one step forward, the next step will require less than the resources needed to make the previous step.

In the context of sustainable, low-carbon development, the diffusion of new norms, principles and standards that reinforce sustainability rationales in collective actions is very likely to occur in a homogenous system rather than in a fragmented one. However, there is a need to analyze what makes the system homogenous, particularly when actors will virtually certainly be diversified. Even in classical 'nation' states such as France and Germany where the population is generally perceived as homogenous, there are differences, depending on which category (language, religion, level of income) is considered. The difference between homogeneity and heterogeneity depends significantly on the socio-technical and socio-linguistic narratives used. These contend which similarities and differences are deemed relevant and which elements of these similarities or differences (us against them) will likely mobilize identity-building. Therefore, there is a need to find a set of categories that highlight similarities without linking differences with threats - a citizenry based on human solidarity.

Congruence 4: At the domestic and global level, power asymmetries need to define the asymmetries of privileges. As power shifts during the transformation process, if structural arrangements and institutions (including norms and practices) are preventing corresponding changes in the distribution of privileges, and status quo agents are successful in maintaining or even expanding old privileges, then individual incentives to defect from the transformation process will likely outweigh the incentives of continued cooperation/collaboration.

Shifts in the underlying structure of power are reflected, sometimes gradually rather than abruptly, by changes in social institutions like regimes at the global level (see Young 2010 p. 175) and in state institutions at the domestic level. While actors accept that power asymmetries are a given, they take the distribution of privileges seriously and contest it, should they find themselves in an unfavorable position. Nevertheless, they will very likely accept the distribution of privileges according to power asymmetries, particularly when this power status is achieved and maintained by costs shouldered by the powerful. However, as soon as power configurations shift, the distribution of privileges is virtually certainly expected to shift as well. If not, the distribution mechanism will be contested and if status quo agents are able to instrumentalize their old privileges to inhibit change in the distribution of privileges, then defection is virtually certain to occur. 
Asymmetries in power are knowledge-intensive. Therefore, the system is very likely to witness an intensive exchange of information. Further, additional 'convening' power can be generated through capacities to introduce indicators and benchmarks that are needed to assess power relations. Therefore, another challenge lies in the empirical and conceptual problems of measuring power, assessing when and how power is shifting, and differentiating paradigmatic shifts from mere one-time, coincidental deviations. In addition, as Oran Young (2010 p. 176) contends, while it is easy to recognize major shifts in power, it is difficult to pin down the preliminary stages of significant shifts, or to monitor them closely as they unfold. The ability of early identification is important, as it allows more time and resources to counter emerging shifts or to adapt to their implications as first movers.

Another challenge is linked with the self-reinforcing characteristic of power, often sustained by privileges, with or without active intervention from the actors. In addition, some privileges are latent, which requires addition effort to be properly conceptualized and resolved. Other privileges are symptomatic. These privileges can be caused by variables that are systems-related, which cannot be resolved without causing additional paradoxes. For example, the underrepresentation of scholars from developing countries in the generation of academic knowledge is not always a result of the intended marginalization of these scholars but can also be attributed to differences in orientation or mandate (e.g., the teaching mandate of professors). This underrepresentation is rather a symptom of 'biased' indicators of the 'performance quality' of scholars, which tend to focus heavily on publications in peer-reviewed journals.

Looking at the international system, emerging powers such as China and Mexico will virtually certainly seek access to privileges enjoyed by contemporary powers, and when confronted by an inability to do so due to existing structural constraints, these emerging powers will very likely evaluate whether defection (and the establishment of competing systems) will bring more benefits. In some cases, emerging powers will establish competing regimes or institutions that will very likely be open only to selected actors. This behavior will likely be interpreted by established powers as rule-breaking and therefore as a threat to international stability and order. In addition, emerging powers will very likely 'shop for forum,' which means that in addressing one issue they will very likely prefer to participate in a specific global institution, but in another issue, they will participate in a competing global or regional institution. This behavior will likely be seen negatively by established parties, because this undermines the predictability and consistency of foreign policies. Therefore, power shifts in transformation processes will very 
likely lead to an international order that is likely more fragmented and therefore polycentric.

Congruence 5: At the global level, if the states are experiencing increased convergence, then the motivation to defect virtually certainly decreases. In other words, the convergence of norms, principles, and practices is both a requirement and an outcome of cooperation.

Convergence refers to the similarities in experiences between actors in terms of lock-ins, standards, and norms. The increased rapprochement of the policies and actions of countries will very likely promote cooperation or collaboration. As convergence increases, the immediate pay-offs of defection likely decreases, because convergence resolves the 'prisoner's dilemma' in collaboration games (see Layer 1980; Snidal 2010). The rapprochement of multiple equilibria in the context of convergence implies that the suboptimal equilibrium's pay-offs will very likely become minimal. Furthermore, it needs to be highlighted that convergence does not automatically mean the elimination of asymmetries between actors. Asymmetries in power or privileges can even promote cooperation. As Duncan Snidal (2010 p. 11) contends, asymmetries increase the likelihood of some cooperation. However, the distribution of benefits from cooperation will very likely reflect this asymmetry, and the discrepancy between the asymmetry and the benefits will virtually certainly lead to contestation. As the distribution of costs and benefits can also favor weaker parties, weaker states will likely perceive that this probability of benefits outweighs complete exclusion.

The negotiation outlook on collective decision-making suggests that cooperation in the context of an unequal distribution of privileges is likely tolerated when the actors are confronted with similarities in terms of lock-ins, standards, and norms, implying that the degree of convergence among actors offsets the legitimacy gaps that resulted from asymmetries in power and privileges. Because convergence implies the ability to reciprocate the behavior of the others, actors expect that they can also profit from the privileges of powerful actors without shouldering the costs of achieving and maintaining power. Therefore, because convergence constitutes the anticipation of spill-over effects, asymmetries become tolerable. In this sense, it can also be argued that the incentives to defect from a transformation process in the context of asymmetries are very likely concretized through convergence.

In addition, it can be argued that actors will very likely allot more time to negotiations with those actors with similar lock-ins compared to those which are perceived as being significantly different. This means, for example, that while countries with the same type of policy pathways (democratic, authoritarian, etc.) 
are expected to prefer negotiations among each other, the caveat to negotiating will likely disappear when the policy pathway taken by the counterparts does not reflect the various lock-ins one is confronted with. In addition, further convergence is achieved as actors explore additional potentials of cooperation, cementing shared values and establishing new capacities, which eventually pave the way for more exclusive membership. Therefore, while convergence promotes further cooperation, it can also limit the scale of cooperation, as actors outside the fractal system (convergent system) will very likely be excluded.

A possible limitation of this congruence is when a specific public good relevant to the transformation process debars the exclusion of non-members, or that the multiple memberships of one actor to more than one 'convergent club' is possible. In addition, countries that are attempting to combine various transformative pathways with contradictory norms and values will very likely be difficult to address. For example, when a country pursues multiple policies that are in their essence contradictory with each other, like aiming to reduce emissions but granting new concessions to coal mining companies, other countries that still intend to engage in cooperation will need to look beyond convergence as orientation. Another limitation to this congruence refers to a situation where information on the other's behavior is limited or can be easily manipulated, because relevant issues are highly politicized or securitized, which compel exceptions to existing rules and practices.

Congruence 6: If critical junctures (and lock-ins), in the context of sustainable, low-carbon transformation, create conflicts in social mandates, then there is very likely a need to find a concept of 'conversion' for the relevant values through a 'common currency.'

Several collaboration and coordination problem-issues were resolved in the last few years as confirmed by the Paris Climate Agreement. The first signs of payoffs from mitigation policies made in the past have already occurred. Examples of these signs include the gradual decrease of upfront costs and the market price of renewables. In addition, the slowing growth in the global $\mathrm{CO}_{2}$ emission level was recorded despite continued economic growth, hinting at stabilization and a slower global growth in fossil fuel consumption (see Jackson et al. 2015; IEA 2016a; Löfken \& Martin 2017). While it is still premature to claim that the critical juncture that favors sustainable, low-carbon seems to have already arrived, signs indicate that this critical juncture is only a matter of time.

This critical juncture is expected to be further reinforced, eventually establishing self-driving lock-ins, as the effects of investments in renewables are realized in the next few years. Since 2015, there have been more energy power plants 
using wind, water, and solar power than those using energy from fossil fuels and nuclear power (IEA 2016a). In addition, 70\% of new investments made (or 288 billion USD) in the electricity sector are attributed to renewables (IEA 2016a) and a significant chunk of these investments were made in China, which is the primary source of emission growth. When this critical juncture is established, distortions, such as the election of President Trump, as the case study on the United States shows, are unlikely to cause major reversals of the transformation process or even a system rupture. On the contrary, there are important silver-linings to such distortions that will very likely further reinforce the transformation process. The relevant climate and sustainability initiatives coming from the private sector and civil society under President Trump, which were not available during previous administrations, are likely promising signs that after the term of President Trump, the sustainable, low-carbon transformation of the United States or even of many developing countries will very likely accelerate. New climate leaders such as China have emerged. Because the Chinese regime has recognized that the decrease of coal use in China was largely responsible for $\mathrm{CO}_{2}$ stabilization, China has garnered the 'moral legitimacy' needed for its leadership.

The road towards this critical juncture is long. Additional efforts and time are needed to promote the required convergence of norms, standards, and values, also due to marginal benefits. This road will virtually certainly demand the further relinquishing of personal rights, liberties, and freedoms at the domestic level and sovereignty at the global level. As new lock-ins emerge, more rights and freedoms may be undermined, which may alter preferences, particularly when benefits remain 'theoretical' and 'collective' while the costs are 'practical' and 'personal'. Because sustainable, low-carbon transformation involves cutting across issues, jurisdictions, and mandates, conflicts of rights and liberties will virtually certainly be inevitable. The failure to adequately address emerging conflicts will very likely further motivate the creation of additional fractals in an already fragmented system.

As hinted at earlier in this book, conversion is inevitable, because identifying benchmarks as well as the contingents of transformation require the comparability of values and, later, of the 'inventories' of a policy that need to be replaced without undermining the overall effectiveness of this policy. The resolution of both coordination and collaboration problems are virtually certainly dependent on benchmarks and contingencies, which will likely cross-cut several issues, rights, and mandates. Therefore, social contracts will very likely need to include mechanisms of conversion to diminish the self-enforcement of existing structural biases. Using the conflict between the German wind energy sector and environmental groups, under current conditions, the offshore wind energy sector will very likely 
produce more compelling arguments to persuade policy-makers and public opinion. The reason behind this is that this sector can easily 'convert' its current and future values into more tangible 'currencies' that are welcomed by policy-makers and the public. For example, the number of jobs that are created and will be created by the sector are compelling. For the environmental groups, it will be difficult to convert 'environmental integrity' into currencies that can equally compel political and public acceptance as much as the arguments of the offshore wind energy sector. How many jobs can one unit of environmental integrity create? Answering this question is not only difficult from the methodological perspective, but it is also difficult because the answer will very likely imply that the others should relinquish rights and liberties and undermine the social mandates of other actors. For example, hypothetically speaking, if one can answer with certainty that one unit of environmental integrity will create 100 jobs, this will very likely mean that the reduction of 100 jobs in the energy sector will be tolerated or demanded, then additional compelling values can be presented by the energy sector such as the economic competitiveness of the city or country. For environmental groups, converting environmental integrity into economic competitiveness may be more difficult to achieve.

The simulation game on the Jamaican austerity measures hinted at the possibility of 'trading' values: risk, unhappiness, and ecological damage points (see the case study on Jamaica). This idea came into the discussion as the participants quantified the risks, unhappiness levels and ecological damage. As the participants focused on the co-benefits and synergies of selected austerity measures, some provisions produced positive externalities for the environment. What if this 'conversion' could be produced in reverse? This would, however, require further theoretical underpinnings.

Congruence 7: If the deliberation over the factors relevant to legitimacy, efficiency, and capacity focus mainly on 'big bang' situations, then it will very likely lose count on the importance of 'low' politics for systemic and social integration.

An upcoming debate about transformative pathways will raise the question of whether a certain transformative pathway can be best achieved through voluntary or binding commitments. An intuitive answer to that is that this pathway needs to be binding to all or to none. Binding commitments can be designed in such a way that non-participation brings less pay-offs or even unacceptable disadvantages. However, as argued earlier, a sustainable, low-carbon transformative pathway will very likely demand limitations and constraints on liberties and freedoms, which also includes the freedom to decide 'unwisely'. Relinquishing certain individual 
rights and liberties to achieve collective sustainable, low-carbon goals will very likely necessitate tedious deliberation, as individual actors will assess the values behind their preferences in terms of incentives. Further inhibiting deliberation is the uncertainty of the future outcomes of present decisions, which motivates actors to agree on commitments that allow exit-strategies.

At the global level, attaining a single, global-wide, sustainable, low-carbon transformation is, under current conditions, perceived to be merely theoretical or academic. A specific unknown threshold needs to be identified, conceptualized and achieved first, through which it would eventually become unbearable to be in an unsustainable, high-carbon system. What can be currently observed, is that one or a small group of states have chosen a 'contextualized', sustainable and low-carbon transformative pathway that addresses local conditions while accommodating global visions. As such, their pathways are contingent upon different 'flexibility' measures, as well as requiring varying bridging technologies that enable transition without less unacceptable sacrifices and steep cuts in their utility values. Nevertheless, the contextualization of pathways virtually certainly demonstrates the diversity of individual 'high' and 'low' politics, which refer to the level of securitization of issues. Securitization implies the willingness to employ coercive measures. Nevertheless, differences in political priorities and indifferences can be tapped to expand values.

The simulation game on Jamaica demonstrated how some participants, who were representing various stakeholders, were able to gain additional pay-offs through issues they were initially indifferent to. Because the issues they were indifferent to were considered to be 'high' politics by the others, they had nothing to lose when they supported the interests of these others. As they were in a bargaining game, their indifferences became integral to the achievement of their 'high' politics. Indifference can therefore provide additional leverage. In the same manner, participants, whose 'high' politics became obvious to the others through their behavior and rhetoric, experienced increased resistance and bargaining intensity, as the others perceived that they could gain more from the participants with clear, 'high' politics. Therefore, if given the chance to repeat the process, these participants will very likely hide their 'high' politics the next time around, increasing the need for ambiguities and further increasing the complexity of interactions.

In addition, appropriate attention needs to be given to the anti-functionalist effect of 'high' politics. Functional interactions imply the systemic and social integration of various utilities, which can be distorted if these interactions involve 'high' politics. In the case study on the Philippines, it was a game-changing event when the appointed Environment Secretary elevated the mining issue as 'high' 
politics, which in turn transformed her confirmation into 'high' politics, in which she had no jurisdiction or bargaining leverage. While the confirmation was initially a formality of appointment, its importance as leverage for her opponents became evident. This demonstrates that policy-makers need to consider how turning an issue into high politics will be very likely translated into other issues, and that one should assess his or her own bargaining leverage in those other issues, including those issues one is indifferent to. Therefore, 'low' politics and 'high' politics should receive equal attention from both policy-makers and academes, as they both offer opportunities and weaknesses when engaging in functional and bargaining interactions. Focusing mainly on 'high' politics will likely imply an underestimation of 'low' politics, which can be easily turned into 'high' politics as the negotiation process unfolds.

Open Access This chapter is licensed under the terms of the Creative Commons Attribution 4.0 International License (http://creativecommons.org/licenses/by/4.0/), which permits use, sharing, adaptation, distribution and reproduction in any medium or format, as long as you give appropriate credit to the original author(s) and the source, provide a link to the Creative Commons license and indicate if changes were made.

The images or other third party material in this chapter are included in the chapter's Creative Commons license, unless indicated otherwise in a credit line to the material. If material is not included in the chapter's Creative Commons license and your intended use is not permitted by statutory regulation or exceeds the permitted use, you will need to obtain permission directly from the copyright holder.

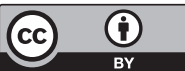

